\title{
Variability of Thinness and its Relation to Cardio-metabolic Risk Factors using Four Body Mass Index References in School-children from Delhi, India
}

\author{
${ }^{1,8}$ Pankaj Garg, ${ }^{2,9}$ Supreet Kaur, ${ }^{3,10}$ Dileep Gupta, ${ }^{4}$ Clive Osmond, ${ }^{5}$ Ramakrishnan Lakshmy, ${ }^{11}$ Shikha \\ SINHA, ${ }^{6}$ UMESH KAPIL, ${ }^{7}$ HPS SACHDEV* \\ From the 1,3, 7,11 Department of Pediatrics and Clinical Epidemiology, Sitaram Bhrtia Institute of Science and Research, B-16, \\ Qutab Institutional Area, New Delhi 110016, India; ${ }^{2,}{ }^{6}$ Departments of Human Nutrition and ${ }^{5}$ Cardiac Biochemistry, All India \\ Institute of Medical Sciences, New Delhi 110029, India; ${ }^{4}$ Medical Research Council Lifecourse Epidemiology Unit, University of \\ Southampton, Southampton General Hospital, Southampton S016 6YD, UK; ${ }^{8}$ Current affiliation: Conjoint Associate Lecturer, \\ School of Women's and Children Health, University of New South Wales and Department of Community Pediatrics, Liverpool \\ Hospital, NSW, Australia; ${ }^{9}$ Current affiliation: Senior Programme Associate, Public Health Foundation of India (PHFI), Vasant \\ Kunj, New Delhi 110070 and ${ }^{10}$ Current affiliation: Statistical Officer, Planning Department, Government of NCT of Delhi, New \\ Delhi 110002. \\ Correspondence to: Prof HPS Sachdev, Senior Consultant Pediatrics and Clinical Epidemiology, E- 6/12, Vasant Vihar, New Delhi \\ 110 057,India.hpssachdev@gmail.com
}

\begin{abstract}
Objectives: To compare: (i) prevalences of thinness in schoolchildren by four body mass index references in common use viz., Centre for Disease Control (CDC); Cole; Indian Academy of Pediatrics (IAP); World Health Organization (WHO); and (ii) relationship of thinness with absence of cardio-metabolic risk factors in these BMI references.
\end{abstract}

Design: Cross-sectional.

Setting: Schools in Delhi.

Participants: Anthropometry and blood pressure were measured in 16,245 school children aged 5 to 18 years. Fasting lipids and blood sugar were estimated in 2796 subjects.

Outcome measures: Age and sex-specific prevalences of thinness and predictive ability of reference cut-off for detecting any cardio-metabolic risk factor were compared.

Results: Prevalence of thinness varied with the reference

employed; more so for boys. Overall prevalence of thinness was least with IAP reference and highest with CDC cut-offs (6.6\% to $16.9 \%$ in boys, $6.5 \%$ to $10.3 \%$ in girls). Children identified as thin by any reference had comparable, significantly lower risks (OR 0.59 to 0.73 ) of associated cardio-metabolic aberrations. In subjects with any cardio-metabolic or blood pressure aberration, the prevalence of thinness was highest with CDC and least with IAP definition.

Conclusion: Prevalence of thinness varies considerably with the reference employed. Thin children, identified by any reference, have a lower risk of associated cardio-metabolic aberrations; however, thinness is a poor diagnostic test for this purpose. In populations undergoing nutrition transition, there is a need to link cardio-metabolic risk factors with recommended anthropometric criteria to define undernutrition.

Keywords: Body mass index, Cholesterol, Glucose, Hypertension, Thinness, Triglyceride.

Published online: June 5, 2013; PII: S097475591200871

A dults below a body mass index (BMI) of 18.5 $\mathrm{kg} / \mathrm{m}^{2}$ are classified as thin or underweight $[1,2]$. This concept has been extrapolated to adolescents and children to develop gender and age-specific BMI cut-offs to assess prevalence of thinness [2,3] in various settings, Centre for Disease Control (CDC) and World Health Organization (WHO) BMI charts are also available for this purpose [4,5]. The availability of multiple cut-offs based on different BMI references poses a challenge both for clinical practice and for quantification of public health burden. Considerable variations in prevalences of obesity (9.3\% to $21 \%$ in boys, $4.1 \%$ to $35 \%$ in girls) and metabolic syndrome abnormalities in anthropometrically obese children are documented with use of different BMI references in various settings [6-11]. Considerable variations may likewise occur for thinness, even in low and middle income countries (LMICs).

The National Family Health Survey (NFHS-3) data from India has documented a high prevalence of undernutrition in children younger than five years using WHO multi-country growth reference $[12,13]$. However, there is paucity of similar nationally representative data in older children and adolescents. The estimated burden of thinness (undernutrition) from future, relevant data sets may be substantially influenced by the choice of growth standard. It is therefore important to understand 
and quantify the variations in prevalences of thinness, if any with the commonly employed, international and national, BMI references in older children and adolescents.

In LMICs, anthropometrically undernourished children are often prescribed food supplementation to improve body size. However, cardio-metabolic risk factors (proxy for overnutrition) can also theoretically occur in a proportion of anthropometrically undernourished children, especially in settings of rapid nutrition transition. In the short-term, food supplementation may worsen cardio-metabolic risk factors in such individuals. In the long term, if this intervention leads to adult overweight or obesity, the propensity to develop chronic diseases and hypertension will increase [14-16]. It is therefore also important to determine if thinness predicts absence of cardiometabolic risk factors and whether this relationship alters with different BMI references.

This study was therefore designed to compare: (i) prevalences of thinness in school-children by four BMI references in common use, namely, Cole, et al. [2], WHO [4], CDC [5] and Indian Academy of Pediatrics (IAP) [17]; and (ii) relationship of thinness with absence of cardio-metabolic risk factors in these BMI references.

\section{Methods}

This cross-sectional study was conducted between January 2005 and March 2007. All the public and private schools in National Capital Territory of Delhi were enlisted and stratified into low (LIG), middle (MIG) and high (HIG) income groups on the basis of fees charged. Government and Municipal Corporation of Delhi schools were considered as LIG, Kendriya Vidhalayas as MIG and private schools charging monthly tuition fees above Rs.1000 as HIG. Probability proportionate to size (PPS) sampling methodology was utilized for selection of 90 schools. In each of the socio-economic group, 30 clusters were selected. We evaluated $180 \pm 10$ subjects, between 5 and 18 years of age, from each cluster. Written informed consent was taken from the school authorities and parents. Institutional ethics approval was granted by the All India Institute of Medical Sciences, New Delhi.

Weight and height were recorded using standard methodology [18]. Weight was recorded on SECA electronic weighing scale to the nearest $100 \mathrm{~g}$. Height was recorded on anthropometric height board to the nearest $0.1 \mathrm{~cm}$. Three readings of height and weight were taken, and the mean of the last two readings was recorded. Systolic and diastolic blood pressures after a period of 10 minutes rest were measured in sitting position with an appropriate sized cuff on a mercury sphygmomanometer. Three readings were taken, and their mean was considered as the individual's blood pressure. All these measurements were recorded by trained nutritionists.

In consenting subjects, $5 \mathrm{~mL}$ of fasting blood sample was transported to laboratory for estimating serum total cholesterol, triglyceride, high density lipoprotein (HDL) and sugar. For quality assurance, three levels of internal controls were run with each batch of twenty samples. The intra-assay and inter-assay variation was less than $2 \%$ and $3 \%$, for cholesterol and triglyceride levels, respectively; and less than 2.5\% and 3.5\% for HDL cholesterol and sugar, respectively. Estimation of total serum cholesterol was done by CHOD-PAP (cholesterol oxidase/paminophenazone) method and triglycerides by GPO-PAP (glycerolphosphate oxidase-peroxidase aminophenazone) method [19,20]. High-density lipoprotein cholesterol (HDL) was estimated by the precipitation method using phosphotungstate/magnesium precipitation of apolipoprotein B containing lipoproteins followed by the estimation of cholesterol in the supernatant by enzymatic method. Low density lipoprotein (LDL) was calculated using Friedewald formula [21]. Fasting glucose was estimated using the standard glucose oxidase method. Estimations of all these biochemical parameters were available in 2796 children (LIG - 626, MIG - 962, HIG-1208).

Pre-hypertension was defined as systolic and diastolic blood pressure between $90^{\text {th }}$ to $95^{\text {th }}$ percentile (z-scores 1.282-1.645), and hypertension $>95^{\text {th }}$ percentile (z-score $>1.645$ ), using the sex and height adjusted Centre for Disease Control (CDC, 2000) standards for the American children [22]. Dyslipidemia (either hypertriglyceredemia $\geq 200 \mathrm{mg} / \mathrm{dL}$, or low HDL cholesterol $<40 \mathrm{mg} / \mathrm{dL}$, or high LDL cholesterol $\geq 100$ $\mathrm{mg} / \mathrm{dL}$ or hypercholesterolemia $\geq 170 \mathrm{mg} / \mathrm{dL}$ ) was defined according to American Heart Association (AHA) guidelines, endorsed by the American Academy of Pediatrics [23]. At these cut-offs dietary and/or life style interventions are suggested [23,24]. Impaired glucose tolerance was defined as fasting plasma glucose levels $\geq 100 \mathrm{mg} / \mathrm{dL}$ [25]. The AHA cut-off values for fasting plasma glucose and HDL cholesterol corresponded with the International Diabetes Federation (IDF) definition of metabolic syndrome in children and adolescents [26]. However, the cut-off for triglyceride was lower $(\geq 1.7$ $\mathrm{mmol} / \mathrm{l}$ or $\geq 150 \mathrm{mg} / \mathrm{dL}$ ) with IDF criteria [26].

Statistics: Statistical analysis was done using SPSS version 13.0 (SPSS Inc, Chicago, Illinois, USA). We had the recorded age to the exact day, which was grouped into 0.1 yearly intervals. However, the cut-off values for BMI 
references were depicted at half-monthly [5], monthly [4], half-yearly [2] and yearly [17] intervals. In order to obtain precise numerical cut-offs at 0.1 yearly intervals, smoothing was required for the intervening time points. This was achieved by polynomial curve regression [27] using the stated cut-offs at different ages [2,4,5,17] as anchors, so that these values remained virtually identical after smoothing. The degree of polynomial used was based on the best fit and varied for the four references (seventh degree for the Cole, CDC and WHO references and fourth degree for IAP reference).

The gender specific age ranges for comparison were identified according to the ages where the smoothed curves of BMI from the four references crossed or touched each other (Fig. 1). Age and sex-specific prevalences of thinness, defined as per the cut-offs recommended by the four BMI references [2,4,5,17], were compared. The cut-offs used were below -2 SD (Z score) for WHO [4] and CDC [5] references; below age and gender specific extrapolation of BMI of 17 at 18 years, which correspond to a mean $\mathrm{Z}$ score of -2 , for Cole et al. [2] reference; and below $5^{\text {th }}$ percentile for IAP reference [17].

Sex and height adjusted Z-scores for systolic and diastolic blood pressure of children were calculated using separate equations as recommended [22]. We also compared the odds ratio, sensitivity, specificity, predictive values and likelihood ratios for detecting any cardio-metabolic risk factor in children identified as thin using various BMI references.

\section{RESUlts}

Subjects consenting for blood-letting were more often females and had significantly greater age, socioeconomic class, height-for-age ( $0.2 \mathrm{Z}$-score), weight-forage (0.8 Z-score) and BMI-for-age (0.5 Z-score) $(P<0.001$ for all variables). The age, gender and socioeconomic class adjusted Odds Ratio (95\% CI) for being sampled per unit increase in BMI-for-age $Z$ score was $1.10(1.09,1.12)$.

Descriptive characteristics of the subjects are summarized in Table I. Overall prevalence of thinness varied between $6.6 \%$ and $16.9 \%$ for boys, and $6.5 \%$ and $10.3 \%$ for girls using IAP and CDC references, respectively (Tables II and III). The differences were more pronounced for boys as compared to girls. Prevalence with IAP reference was substantially lower than CDC reference for boys across all the age ranges (least for the age range 14.6 to 18.0 years) (Table II). Thinness prevalence in boys using the CDC and Cole

TABLE I DESCRIPTIVE CHARACTERISTICS OF THE STUDY POPULATION

\begin{tabular}{|c|c|c|c|c|}
\hline \multirow[t]{2}{*}{ Income group (Number) } & \multirow[t]{2}{*}{ Mean (SD) age (yrs) } & \multirow[t]{2}{*}{ Mean BMI $\left(\mathrm{kg} / \mathrm{m}^{2}\right)(S D)[$ range] } & \multicolumn{2}{|c|}{ Sex } \\
\hline & & & Male & Female \\
\hline LIG (5031) & $12.1(3.5)$ & $16.37(2.7)[11.2-32.8]$ & 2378 & 2653 \\
\hline MIG (5119) & $11.6(3.3)$ & $16.96(3.1)[11.2-36.7]$ & 2736 & 2383 \\
\hline HIG (6095) & $11.5(3.1)$ & $18.71(4.5)[11.0-39.3]$ & 3199 & 2896 \\
\hline Total 16245 & $11.7(3.3)$ & $17.44(3.7)[11.0-39.3]$ & 8313 & 7932 \\
\hline
\end{tabular}

BMI - Body mass index; HIG - High income group; LIG - Low income group; MIG - Middle income group.

TABLE II PREVALENCE OF THINNESS In BOys ACCORDING TO FOUR BMI REFERENCES

\begin{tabular}{|c|c|c|c|c|c|c|c|c|c|c|c|c|c|c|}
\hline \multirow{3}{*}{ Reference $^{a}$} & \multicolumn{12}{|c|}{ Years } & & \\
\hline & \multicolumn{2}{|c|}{$5.0-6.5$} & \multirow[t]{2}{*}{ Ref } & \multicolumn{2}{|c|}{$6.6-9.5$} & \multicolumn{2}{|c|}{$9.6-12.0$} & \multicolumn{2}{|c|}{$12.1-14.5$} & \multicolumn{2}{|c|}{$14.6-18.0$} & \multirow[t]{2}{*}{ Ref } & \multicolumn{2}{|c|}{$5.0-18.0$} \\
\hline & $n$ & $\%$ & & $\bar{n}$ & $\%$ & $n$ & $\%$ & $n$ & $\%$ & $n$ & $\%$ & & $\bar{n}$ & $\%$ \\
\hline $\mathrm{CDC}$ & 83 & 18.2 & CDC & 203 & 11.0 & 233 & 13.4 & 423 & 19.3 & 460 & 22.0 & $\mathrm{CDC}$ & 1402 & 16.9 \\
\hline Cole & 49 & 10.7 & WHO & 154 & 8.4 & 211 & 12.2 & 413 & 18.8 & 423 & 20.3 & WHO & 1237 & 14.9 \\
\hline WHO & 36 & 7.9 & Cole & 111 & 6.0 & 127 & 7.3 & 281 & 12.8 & 301 & 14.4 & Cole & 869 & 10.5 \\
\hline IAP & 20 & 4.4 & IAP & 80 & 4.3 & 53 & 3.1 & 175 & 8.0 & 217 & 10.4 & IAP & 545 & 6.6 \\
\hline All $^{\mathrm{b}}$ & 456 & & & 1844 & & 1733 & & 2193 & & 2087 & & & 8313 & \\
\hline
\end{tabular}

${ }^{a}$ The references in each age interval are ordered according to the cut-off value in descending order; ${ }^{b}$ total number of subjects in the age range. 


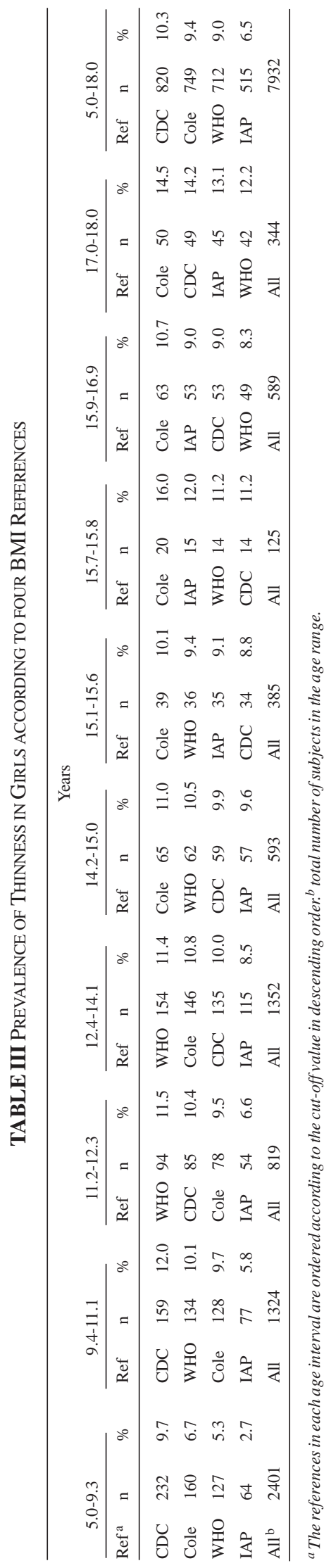

INDIAN PEDIATRICS

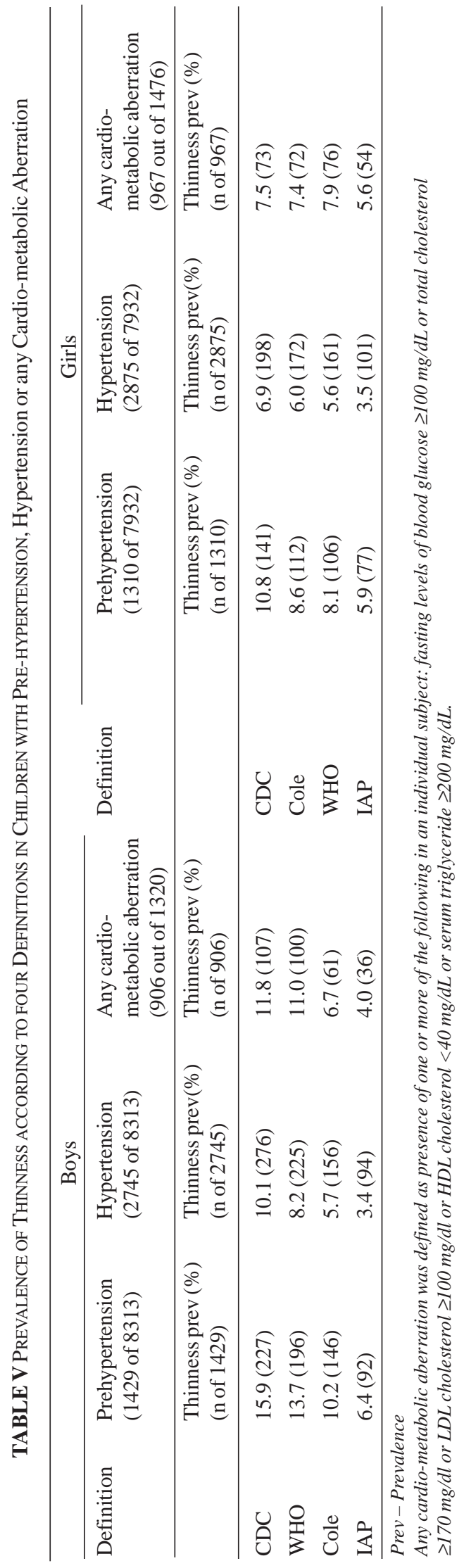

1028 
TABLE IV COMPARISON OF FOUR THINNESS CUT-OFFS FOR DIAGNOSING ANY CARDIO-METABOLIC ABERRATION

\begin{tabular}{llllllll}
\hline $\begin{array}{l}\text { Thinness } \\
\text { cut-off }\end{array}$ & $\begin{array}{l}\text { Odds ratio (95\% } \\
\text { CI; } \text { P value }\end{array}$ & Sensitivity & Specificity & $\begin{array}{l}\text { Positive } \\
\text { predictive } \\
\text { value }\end{array}$ & $\begin{array}{l}\text { Negative } \\
\text { predictive } \\
\text { value }\end{array}$ & $\begin{array}{l}\text { Positive } \\
\text { likelihood } \\
\text { ratio }\end{array}$ & $\begin{array}{l}\text { Negative } \\
\text { likelihood } \\
\text { ratio }\end{array}$ \\
\hline CDC & $0.73(0.57,0.93) ; 0.011$ & 0.10 & 0.87 & 0.60 & 0.32 & 0.75 & 1.04 \\
WHO & $0.73(0.56,0.93) ; 0.012$ & 0.09 & 0.88 & 0.60 & 0.32 & 0.75 & 1.03 \\
Cole & $0.62(0.48,0.81) ; 0.001$ & 0.07 & 0.89 & 0.57 & 0.32 & 0.65 & 1.04 \\
IAP & $0.59(0.43,0.81) ; 0.001$ & 0.05 & 0.92 & 0.55 & 0.32 & 0.61 & 1.03 \\
\hline
\end{tabular}

Any cardio-metabolic aberration was defined as presence of one or more of the following in an individual subject: fasting levels of blood glucose $\geq 100 \mathrm{mg} / \mathrm{dl}$ or total cholesterol $\geq 170 \mathrm{mg} / \mathrm{dl}$ or LDL cholesterol $\geq 100 \mathrm{mg} / \mathrm{dl}$ or HDL cholesterol $<40 \mathrm{mg} / \mathrm{dl}$ or serum triglyceride $\geq 200 \mathrm{mg} / \mathrm{dl}$. Odds Ratios were computed by logistic regression analysis and pertain to comparison of thin with non-thin subjects.

references was $18.2 \%$ and $10.7 \%$, respectively compared to $7.9 \%$ and $4.4 \%$ using WHO and IAP references for the age range of 5.0 to 6.5 years (Table II). After this age range, prevalence with WHO reference was lower than CDC reference but higher than Cole, et al. [2] reference. Prevalence by Cole, et al. [2] reference was closer to IAP reference in boys above 6.5 years.

Crossing over of references was more frequent in girls. In girls, maximum variation was seen in youngest age range (5.0-9.3 years). Prevalence with IAP reference was consistently lower compared to other references till the age of 15 years, after which there were no substantial differences between the references. The WHO cut-off estimated lower prevalence in girls after the age of 15.6 years; whereas, CDC cut-off documented lower prevalence after the age of 12.3 years (Table III).

Children identified as thin by any reference had a significantly lower risk of associated cardio-metabolic risk factors (Table IV); IAP cut-off had the least odds ratio (0.59) but this was not significantly different from the other three references (overlapping confidence intervals). Among children with pre-hypertension, hypertension or any cardio-metabolic aberration, the prevalence of thinness was highest with CDC and least with IAP definition (Table $\mathbf{V} ; P<0.01$ ). These differences were greater in boys ( 2.5 to 3 fold) than in girls (1.3 to 2 fold). In boys the thinness prevalence was greater with WHO in comparison to Cole reference, but the converse was true for girls.

\section{DISCUSSION}

The prevalence of thinness varied with the reference employed, especially in boys. In comparison to IAP reference, CDC reference overestimated thinness maximally (2-4 fold in boys and up to 3.5 fold in girls). This overestimation was lower with WHO and Cole references. Children identified as thin by any reference had comparable, significantly lower risks of associated cardio-metabolic aberrations. However, in subjects with any cardio-metabolic or blood pressure aberration, the prevalence of thinness was highest with CDC and least with IAP definition.

We have evaluated a large sample of urban school children from different socio-economic strata in a developing country undergoing nutrition transition [13]. Simultaneous differences in the prevalences of anthropometric thinness and cardio-metabolic aberrations warranting interventions [23-26] were quantified. Serum biochemistry was performed in an international quality controlled laboratory.

The following limitations merit consideration: (i) We could not adjust for the influence of pubertal growth spurts on BMI as sexual maturity staging was not done. However, this has little relevance as the four evaluated references do not recommend such adjustment for quantifying thinness; (ii) In comparison to other criteria, IAP reference [17] had an uncharacteristic shape for boys, especially above 16 years (Fig. 1). This is not due to our smoothing for intervening age-periods but probably reflects weaknesses in original IAP reference small sample sizes at these ages and not using the recommended LMS method for smoothing. Nevertheless, this has no implications for our stated objectives, because thinness will be categorized according to the depicted cut-offs; (iii) Blood sampled participants had significant differences from others including a higher BMI. This has implications for determining overall prevalence of cardio-metabolic risk factors but not for evaluating their relationship with thinness; (iv) The high prevalence of pre-hypertension and hypertension needs cautious interpretation. We used CDC percentiles for defining height adjusted pre-hypertension and hypertension rather than an Indian reference to maintain uniformity with other biochemical cut-offs. In comparison to unadjusted 

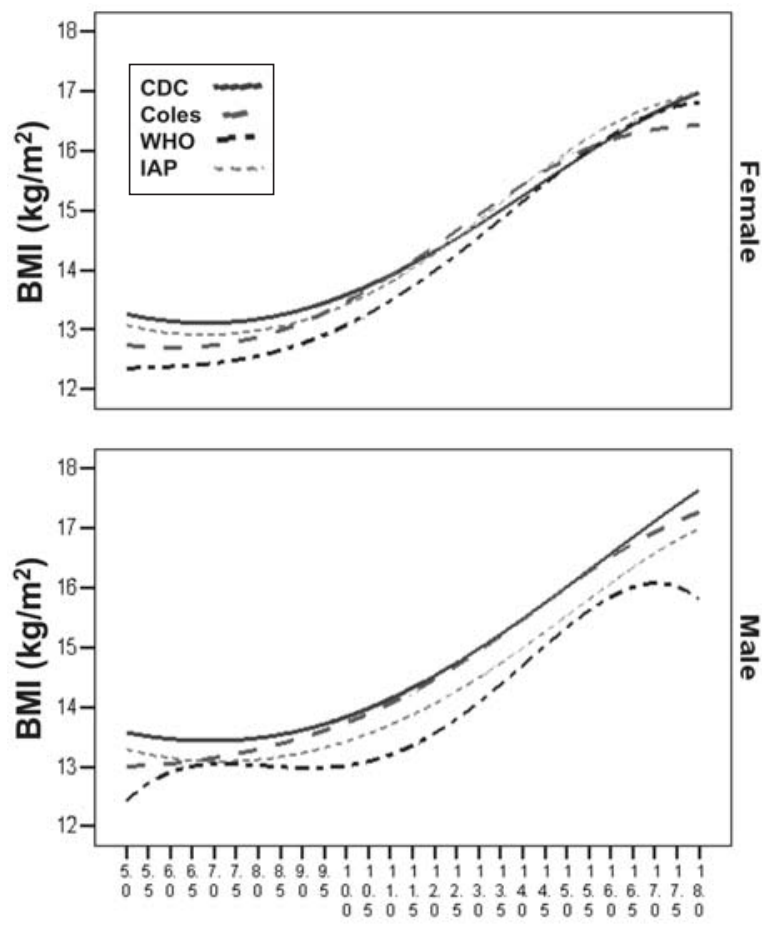

Age(yrs)

Fig.1 Comparison of smoothed curves for body mass index limits for defining thinness.

estimates as in many earlier studies, height adjustment lowers the reference BP thereby inflating the prehypertension and hypertension prevalence in shorter populations as in New Delhi (mean height SD score 0.73). We also acknowledge the inherent challenges of blood pressure measurements in children [28]. Blood pressure was recorded during one visit only, which may not reflect sustained hypertension. Among 15-16 year old students from Dallas, USA with elevated BP $\left(\geq 95^{\text {th }}\right.$ percentile) at initial examination, only $17 \%$ had sustained elevated BP over 2 subsequent visits in the same year [29]. Other studies also indicate that the majority of children with elevated $\mathrm{BP}$ at a given visit have normal BP at subsequent visits a few weeks later, notably because of regression to the mean and habituation to the measurement procedure [28]. It would thus have been ideal for us to perform two repeat BP measurements; however, paucity of resources precluded this possibility. A high prevalence of systolic or diastolic incident hypertension in children (17.3\% in overweight vs. 10.1\% in others) has been shown in a study on a mixed rural and urban Southern Indian population [30]. Thus the overestimation of blood pressure from a single visit in our data from urban area may not be substantial; and ( $v$ ). A larger sample size would have provided greater power to detect the observed differences in predictive abilities of the references for identifying absence of any cardiometabolic aberration.

We are unaware of any similar studies comparing the prevalences of cardio-metabolic aberrations in thin children. However, anthropometric and metabolic discordance has been documented in "metabolically obese normal weight" children in a nationally representative sample from Iran [31]. Several studies have documented variations in prevalences of obesity and metabolic syndrome in children and adolescents with use of different references [6-11]. In younger children, overestimation of prevalence of undernutrition with CDC reference has been documented in both developing and developed countries [32-35]. We used cut-off criteria for which nutritional and/or lifestyle interventions are suggested by the AHA [22-25]. The use of IDF definition [26] increased the prevalence of hyper-triglyceridemia from $2.1 \%$ to $10.5 \%$ without much difference for any cardio-metabolic aberration (67\% vs. 68\%).

From a clinician's perspective, labeling of an individual child as "thin" leads to further diagnostic and therapeutic actions. Absence of data comparing the appropriateness of the management interventions with various cut-offs leads to uncertainty on the utility of one BMI reference over other. Routine recording of blood pressure after the age of three years is recommended in developed country settings to counter obesity related hypertension [24]. It may be a good practice for pediatricians in India to replicate this guideline irrespective of BMI status. Similarly, there may be a case for evaluating the metabolic profile in "at risk" thin children as identified by high blood pressure or a parental history of premature coronary artery disease, hypertension, diabetes mellitus or dyslipidemia. Future research on the utility of these recommendations is required.

In a public health setting, two-to four-fold relative variations in prevalences of thinness have socio-political implications for ranking the development status and progress of nations. Unlike the WHO growth references for under-five children that are conceptualized on prescriptive practices, these evaluated BMI cut-offs are based on statistical charts, which have not been linked to important biological or functional consequences [36,37]. The usual public health and clinical response in thin children is to recommend food supplementation [38,39], which has the potential to worsen cardio-metabolic risk factors including blood pressure. Children identified as thin by any reference had a significantly lower risk of cardio-metabolic aberration (positive likelihood ratios of 0.61 to 0.75 for detecting cardio-metabolic aberration). 
Opinions will vary on the usefulness of these predictions. However, according to conventional guidelines [40], such likelihood ratios of $<0.2$ are generally considered important clinically while values $>0.5$ are labeled worthless.

Biomarkers can be considered as more proximate reflectors of recent nutritional balance; thus cardiometabolic aberrations reflect metabolic overnutrition, even in anthropometrically thin ("undernourished") subjects. In this context, from a public health perspective, national reference has the advantage of detecting the least prevalence of thinness in metabolically overnourished individuals. However, further research is needed to validate these findings in different settings.

In conclusion, prevalences of thinness in schoolchildren vary considerably with the reference employed, especially in boys. Thin children, identified by any reference, have a lower risk of associated cardiometabolic aberrations; however, thinness is a poor diagnostic test for this purpose. In populations undergoing nutrition transition, there is a need to link cardio-metabolic risk factors with recommended anthropometric criteria to define undernutrition.

Acknowledgements: We thank Lieutenant Colonel Dr. Rajat Prakash for training nutritionists, Supreet Kaur (SK), Lakshmi Labani (LL) and Shikha Shukla (SS) for anthropometric and blood pressure measurements.

Contributors: HPSS, UK and PG: conceived the study, analysis and co-drafted the manuscript; CO, HPSS, DG, SS and PG: were responsible for data management and analysis; UK and SK: were responsible for the field work including blood sampling and anthropometry; RL: was responsible for laboratory analyses and their quality control; All the authors contributed to and approved the submitted version; HPSS and UK: will act as co-guarantors. Funding: Indian Council of Medical Research (ICMR); Competing interests: None stated.

\section{REFERENCES}

1. Bailey KV, Ferro-Luzi A. Use of body mass index of adults in assessing individual and community nutritional status. Bull WHO. 1995;73:673-80.

2. Cole TJ, Flegal KM, Nicholls D, Jackson AA. Body mass index cut offs to define thinness in children and adolescents: international survey. BMJ. 2007;335:194201.

3. Cameron N. Body mass index cut offs to define thinness in children and adolescents. BMJ. 2007;335:166-7.

4. World Health Organization. Growth reference 5-19 years: BMI-for-age (5-19 years). Available at http:// www.who.int/growthref/who2007_bmi_for_age/en/ index.html (Accessed December 28, 2012).

5. Centers for Disease Control and Prevention. Growth charts: Z score data files. Available at http://www.cdc.gov/ growthcharts/zscore.htm (Accessed December 28, 2012).
6. Al-Sendi AM, Shetty P, Musaiger AO. Prevalence of overweight and obesity among Bahraini adolescents: a comparison between different sets of criteria. Eur J Clin Nutr. 2003;57:471-4.

7. O’Neill JL, McCarthy SN, Burke SJ, Hannon EM, Kiely M, Flynn A, et al. Prevalence of overweight and obesity in Irish school children, using four different definitions. Eur J Clin Nutr. 2007;61:743-51.

8. Ko GT, Ozaki R, Wong GW, Kong AP, So WY, Tong PC, et al. The problem of obesity among adolescents in Hong Kong: a comparison using various diagnostic criteria. BMC Pediatr. 2008;8:10.

9. Lee S, Bacha F, Gungor N, Arslanian S. Comparison of different definitions of pediatric metabolic syndrome. Relation to abdominal adiposity, insulin resistance, adinopectin, and inflammatory biomarkers. J Pediatr. 2008;152:177-84.

10. Ford ES, Li C. Defining the metabolic syndrome in children and adolescents: Will the real definition please stand up? J Pediatr. 2008;152:160-4.

11. Reinehr T, de Sousa G, Toschke AM, Andler W. Comparison of metabolic syndrome prevalence using eight different definitions: a critical approach. Arch Dis Child. 2007;92:1067-72.

12. National Family Health Survey-3. Available http:// www.nfhsindia.org/volume_1.html (Accessed 1st April 2008).

13. Shetty PS. Nutrition transition in India. Public Health Nutr. 2002;5:175-82.

14. Sawaya AL, Sesso R, Florêncio TM, Fernandes MT, Martins PA. Association between chronic undernutrition and hypertension. Matern Child Nutr. 2005;1:155-63.

15. Stein AD, Thompson AM, Waters A. Childhood growth and chronic disease: evidence from countries undergoing the nutrition transition. Matern Child Nutr. 2005;1:177-84.

16. Victora CG, Adair L, Fall C, Hallal PC, Martorell R, Richter L, et al. Maternal and child under-nutrition: consequences for adult and human capital. Lancet. 2008;371:340-57.

17. Khadilkar VV, Khadilkar AV, Choudhury P, Agarwal KN, Ugra D, Shah NK. IAP growth monitoring guidelines for children from birth to 18 years. Indian Pediatr. 2007;44:187-97.

18. Physical status: the use and interpretation of anthropometry: report of a WHO expert committee. World Health Organ Tec Rep Ser. 1995;854:329.

19. Lolekha PH, Srisawasdi P, Jearanaikoon P, Wetprasit N, Sriwanthana B, Kroll MH. Performance of four sources of cholesterol oxidase for serum cholesterol determination by the enzymatic end point method. Clinica Chimica Acta. 2004;339:135-45.

20. Henkel E, Stoltz M. A newly drafted color test for the determination of triglycerides convenient for manual and mechanized analysis (glycerolphosphate-oxidase-PAP). Fresenius J Anal Chem. 1982;311:451-2.

21. Friedewald WT, Levy RI, Fredrickson DS. Estimation of the concentration of low-density lipoprotein cholesterol in plasma, without use of the preparative ultracentrifuge. Clin Chem. 1972;18:499-502. 
22. National High Blood Pressure Education Program Working Group on High Blood Pressure in Children and Adolescents. The Fourth Report on the Diagnosis, Evaluation, and Treatment of High Blood Pressure in Children and Adolescents. Pediatrics. 2004;114:555-76.

23. Gidding SS, Dennison BA, Birch LL, Daniels SR, Gillman MW, Lichtenstein AH, et al. Dietary recommendations for Children and Adolescents: A guide for Practitioners: Consensus Statement from the American Heart Association. Circulation. 2005;112:2061-75.

24. Williams CL, Hayman LL, Daneils SR, Robinson TN, Steinberger J, Paridon S, et al. Cardiovascular Health in Childhood: A statement for health professionals from the Committee on Atherosclerosis, Hypertension, and Obesity in the Young (AHOY) of the council on cardiovascular disease in the young, American Heart Association. Circulation. 2002;106:143-60.

25. Kavey RE, Allada V, Daniels SR, Hayman LL, McCrindle BW, Newburger JW, et al. Cardiovascular risk reduction in high-risk pediatric patients: A scientific statement from the American Heart Association (AHA) expert panel on population and prevention science; the councils on cardiovascular disease in the young, epidemiology and prevention, nutrition, physical activity and metabolism, high blood pressure research, cardiovascular nursing, and the kidney in heart disease; and the Interdisciplinary working group on quality of care and outcomes research. Circulation. 2006;114:2710-38.

26. Zimmet P, Alberti G, Kaufman F, Tajima N, Silink M, Arslanian S, et al. The metabolic syndrome in children and adolescents. Lancet. 2007;369:2059-61.

27. Zar JH. Polynomial regression. In: Zar JH, editors. Biostatistical Analysis. $4^{\text {th }}$ ed. New Jersey: Prentice Hall; 1999. p. $452-7$.

28. Chiolero A, Bovet P, Paradis G. Screening for elevated blood pressure in children and adolescents. A critical appraisal. JAMA Pediatr. Published online January 7, 2013. doi:10.1001/jamapediatrics.2013.438.

29. Fixler DE, Laird WP. Validity of mass blood pressure screening in children. Pediatrics. 1983;72:459-63.

30. Raj M, Sundaram KR, Paul M, Deepa AS, Kumar KR. Obesity in Indian children: Time trends and relationship with hypertension. Natl Med J India. 2007;20:288-93.

31. Kelishadi R, Cook SR, Motlagh ME, Gouya MM, Ardalan
G, Motaghian M, et al. Metabolically obese normal weight and phenotypically obese metabolically normal youths: the CASPIAN study. J Am Diet Assoc. 2008;108:82-90.

32. de Onis M, Onyango AW, Borghi E, Garza C, Yang H. Comparison of the World Health Organization child growth standards and the National Centre for Health Statistics/WHO international growth reference: implications for child health programmes. Public Health Nutr. 2006;9:942-7.

33. Deshmukh PR, Dongre AR, Gupta SS, Garg BS. Newly developed WHO standards: implications for demographic surveys and child health programs. Indian J Pediatr. 2007;74:987-90.

34. Roberfroid D, Lerude MP, Pérez-Cueto A, Kolsteren P. Is the CDC 2000 growth reference appropriate for developing countries? Public Health Nutr. 2006;9:266-8.

35. Kelishadi R, Ardalan G, Gheiratmand R, Majdzadeh R, Hosseini M, Gouya MM, et al. Thinness, overweight and obesity in a national sample of Iranian children and adolescents: CASPIAN study. Child Care Health Dev. 2008;34:44-54.

36. Seidell JC, Doak CM, de Munter JS, Kuijper LD, Zonneveld C. Cross sectional growth references and implications for the development of an international growth standard for school-aged children and adolescents. Food Nutr Bull. 2006;27:S189-98.

37. Himes JH. Long term longitudinal studies and implications for the development of an international growth reference for children and adolescents. Food Nutr Bull. 2006;27: S199-211.

38. Greenhalgh T, Kristjansson E, Robinson V. Realistic review to understand the efficacy of school feeding programmes. BMJ 2007; 335: 858-61.

39. Kristjansson EA, Robinson V, Pettiscrew M, MacDonald B, Krasevac J, Janzel L, et al. School feeding for improving the physical and psychosocial health of disadvantaged elementary school children. Cochrane Database Syst Rev 2000; 24:CD004676.

40. Jaeschke R, Guyatt G, Lijmer J. Diagnostic tests. In: Users’ Guides to the Medical Literature. Essentials of Evidence Based Clinical Practice. The Evidence-Based Medicine Working Group. Eds. Guyatt G, Rennie D. JAMA and Archives Journals, American Medical Association Press, 2004; p. 187-217. 